ORIGINAL ARTICLE

\title{
Investigation of Body Perceptions of Karate Athletes
}

\author{
AYDIN ILHAN ${ }^{1}$, AYNUR BAYHAR², HAYRETTIN GUMUSDAG ${ }^{3}$ \\ 1,2Pamukkale University, Faculty of Sport Sciences, Denizli, Turkey \\ ${ }^{3}$ Yozgat Bozok University, Faculty of Sports Sciences, Yozgat, Turkey \\ A. Ilhan: https://orcid.org/0000-0001-9717-2746 \\ A. Bayhar: https://orcid.org/0000-0002-2227-7751 \\ H. Gumusdag: https://orcid.org/0000-0002-1616-8671 \\ Corresponding author: Aydin Ilhan, Pamukkale University, Faculty of Sport Sciences, Denizli, Turkey, Contact: +905323941089 , \\ Email: trainertennis@hotmail.com
}

\begin{abstract}
Background: Sports are part of the social life we live in. Sports have an important role in the social, physical, mental and spiritual development of individuals. It has a significant effect on the individual's selfconfidence, development of his character, being a social person, development of practical thinking ability, and mental and physical development. One of the ways used for the desired body structure is physical activity. They had the chance to reach a new physical appearance through physical activities. They have a new physical appearance and positive thoughts [1]. Self-perception is positively affected by participation in sports. From this point of view, examining it with different variables causes us to learn various ways to increase the effect of self-concept.

Aim: The aim of this study is to examine the relationship between the body perceptions of karate athletes, gender, sport age, and generation levels.

Place \& Duration: Data was collected in Turkey. Study duration September 2019 to May 2020.

Methods: The research group consisted of 303 people between the ages of 12 and 20 who practiced karate in Turkey. Data collection tools 'Personal Information Form' and 'Physical Self-Perception Inventory for Children and Adolescents' scale were used. The relationships between the body perceptions of karate athletes, gender, sport age and generation levels were examined. The obtained data were made according to Shapiro Wilk normality analysis and it was determined that all variables did not show normal distribution. All analyzes were performed non-parametrically

Results: The differences in body perceptions of 303 karate athletes in Turkey according to gender, sport age and generation levels were examined in this study, no statistically significant difference was found between the genders, sport ages and generation levels of the participants.

Conclusion: There was no significant difference between body perceptions and gender, sport age and generation levels in karate athletes.

Keywors: Karate, Body Image, Adolescence
\end{abstract}

\section{INTRODUCTION}

Sports are part of the social life we live in. Sports have an important role in the social, physical, mental and spiritual development of individuals. It has a significant effect on the individual's self-confidence, development of his character, being a social person, development of practical thinking ability, and mental and physical development. One of the ways used for the desired body structure is physical activity. They had the chance to reach a new physical appearance through physical activities. They have a new physical appearance and positive thoughts [1]. Japanese karate consists of three words. It means black (empty), te (hand) and do (road). It means the way of the empty hand. It is a defense-oriented art that takes place without weapons using only hands and feet. It reveals it with a philosophy called Do [2]. Karatedo is the art of unarmed struggle with empty hands [3]. There are seven levels of generations in total in the art of karate; are white, yellow, orange, green, blue, brown and black. Darkening of colors means that the athlete matures mentally and physically [4]. Body image has been defined in different ways in different disciplines but focuses on a single aspect. The concept of body image includes features such as body image, shape and form of the body, the concept of body image and the emotions related to them [5]. The relationship between selfconcept and sports has been revealed by many researchers. Researchers emphasized that playgrounds, sports halls, in short, sports are a tool for the development of positive self-concept, that movement gives the person the opportunity to find his own world, and that he has the opportunity to understand the emotions of the person through sports [6]. Within the framework of the researches carried out to reveal the effect of exercise on body image satisfaction and self-esteem, researchers; They stated that there may be an indirect relationship between self-esteem, body image satisfaction and exercise. But there are studies that do not support this [7]. Physical appearance has an important place in people's lives today as it has throughout history. By making publications that support socially accepted, attractive and weak female and muscular male figures, printed and visual communication tools increase the society's desire to resemble these ideal figures and cause people to perceive their own bodies in a positive or negative way [8]. The individual's satisfaction or dissatisfaction with his body plays a role in his interaction with the outside world, in his interpersonal relations, in the development of positive or negative feelings, thoughts and behaviors towards himself. The satisfaction that different parts of the body give to the person is related to the person's self-confidence. A person's height, weight, body size, health status, face, self-worth, and self-behavior that control one's abilities are all reflected in his social relations 
[9]. The purpose of this research is to examine the body perceptions of karate athletes in terms of gender, sport age and generation levels.

\section{METHODS}

Subjects: As the design of the research, descriptive and quantitative research method was used because of examining the interactions between the variables of gender, sport age and generation level of karate athletes. The research group consisted of 38,000 athletes between the ages of 12 and 20 who practiced karate licensed in Turkey. A total of 303 people were reached. The karate players, 108 are female and 195 are male.

Data Collection Tools: The 'Physical Self-Perception Inventory for Children and Adolescents' scale and the 'Personal Information Form' developed by the researcher were used as data collection tools in the study.

It was developed by [10]. and adapted into Turkish by [11]. CY-PSPP consists of 6 sub-dimensions and 30 items: sportive competence, body attractiveness, strength competence, conditioning competence, general physical self-worth and general self-worth. There are 6 items in each sub-dimension. Ethics commission permissions were obtained from Pamukkale University Ethics Committee. Participants are based on volunteerism.

Statistical Analyses: While examining the relationships between the variables of gender, sport age and generation level of body perceptions of karate athletes, it was determined that all variables did not show normal distribution according to descriptive statistics and Shapiro Wilk normality analysis of the data obtained, and all analyzes were made nonparametrically. SPSS 20.0 program was used to calculate the analyzes.

\section{RESULTS}

Table 1. Profile of Karate Athletes

\begin{tabular}{|l|l|l|}
\cline { 2 - 3 } \multicolumn{1}{c|}{} & $\mathrm{N}$ & Age \\
\hline Women & 108 & $14,50 \pm 0,53$ \\
\hline & & \\
\hline Men & 195 & $17,50 \pm 0,45$ \\
\hline
\end{tabular}

According to Table 1, karate athletes profile.

Table 2. Analysis table of body perceptions of karate athletes by gender

\begin{tabular}{|l|l|l|l|l|}
\cline { 2 - 5 } \multicolumn{1}{c|}{} & Mean & Sd & U & P \\
\hline Women & 286.0 & 110.8 & \multirow{2}{*}{10483.5} & \multirow{2}{*}{0.2} \\
\hline Men & 303.0 & 102.1 & & \\
\hline
\end{tabular}

According to Table 2, there was no significant difference between the genders of karate athletes and their body perception levels, according to the results of Mann Whitney $U$ analysis performed to understand whether there is a significant difference between the body perception levels of the karate athletes according to their genders.

Table 3. Analysis table of body perceptions of karate athletes according to sports age

\begin{tabular}{|l|l|l|l|l|}
\cline { 2 - 5 } \multicolumn{1}{c|}{} & Mean & Sd & $U$ & $P$ \\
\hline 6-5 year & 289.8 & 105.5 & \multirow{2}{*}{8298.0} & 0.2 \\
\hline
\end{tabular}

According to table 3 , the results of Mann Whitney $U$ analysis conducted to understand whether there is a significant difference between the body perception levels of karate athletes according to their sports ages, there is a significant difference between the body perception levels of karate athletes with a sports age of 1-5 years and karate athletes with a sports age of 6-10 years. not found.

Table 4. Analysis table of body perceptions of karate athletes according to generation level

\begin{tabular}{|c|c|c|c|c|}
\hline & Mean & $\mathrm{Sd}$ & $\chi^{2}$ & $p$ \\
\hline 1 & 291.93 & 100.58 & \multirow{7}{*}{13.15} & \multirow{7}{*}{0.2} \\
\hline 2 & 282.47 & 119.59 & & \\
\hline 3 & 342.94 & 86.64 & & \\
\hline 4 & 286.95 & 97.78 & & \\
\hline 5 & 339.34 & 103.42 & & \\
\hline 6 & 300.59 & 99.26 & & \\
\hline 7 & 300.87 & 110.48 & & \\
\hline
\end{tabular}

According to table 4, the results of Kruskal Wallis analysis, a significant difference was not found between the body perception levels of karate athletes according to their generation levels.

\section{DISCUSSION}

The aim of this study is to examine the relationship between the body perceptions of karate athletes, gender, sport age, and generation levels. Results showed that Body perception levels of karate athletes do not show a significant difference according to gender. According to the literature, we see that some studies show parallelism with our study. One of them is that individuals who come to bodybuilding and fitness centers do not differ significantly according to their age and gender [12].

In some studies, it is seen that the results obtained differ. In the light of the findings obtained by considering the gender variable in these studies, the scores of the female individuals participating in the study of the selfesteem scale in our study were found to be higher than the male participants. They stated that women's self-esteem scores were higher than men's [13,14]. In another study conducted on female and male football players, there are significant differences in personality traits, In addition, female athletes have higher self-perception levels than men, It has been determined that footballer women are satisfied with their bodies in a positive way [15].

Body perception levels of karate athletes do not show a significant difference according to sports age. According to the results of the analysis, there was no significant difference between the body perception levels of the karate athletes with a sports age of 1-5 years and the karate athletes with a sports age of 6-10 years. This finding obtained from the research differs from the findings obtained from the studies conducted on the subject on various sample groups. In a study conducted to investigate the personality structures and body perception levels of athletes at the national team level, it was determined that athletes who started sports early perceived their own bodies better than those who started sports at an older age, and as their body perception increased, their personal and social harmony increased [16]. Body dissatisfaction scale was applied to determine whether the women who do and do not do sports are satisfied with their bodies, and it was determined that non-athlete women were more dissatisfied with their bodies than athletes [17, 18]. 
According to the results of the analysis, a significant difference was not found between the body perception levels of the karate athletes according to the generation levels.

\section{CONCLUSIONS}

In this study, the body perceptions of 303 karate athletes in Turkey were examined by looking at the significant differences between each other according to gender, sport age and generation levels. As a result of the study, no statistically significant difference was found between the gender, sports age and generation levels of the participants. In terms of researchers, more research should be conducted and comprehensive studies should be carried out on behalf of the factors for which no clear conclusions could be reached. Despite the age groups that make up the universe of our research, comparison and analysis by other researchers by considering the category of adults can make it easier to predict the situation of karate athletes depending on certain variables.

\section{REFERENCES}

1. Cok, F., Body image Satisfaction in Turkish Adolescents. Adolescence, 1990. 25(98): p. 409-414.

2. Alkan, N., Colaklar, A., Shito Ryu. Karate-Do, 2001. Ankara.

3. Hausner, T., Leiter der Medizinischen Kommission des Österreich. Karate Bund, Medizinisches Handbuch Lübeck, 2000. Almanya. P. 78

4. Doganer, A., Doganer, O., Karate-Do. İstanbul. Budokan Publications, 1979. 5(8): p. 63.

5. Alagul, O., The Relationship between Assertiveness and Body Perception of Athletes in Different Sports Branches. Ege University, Institute of Health Sciences, 2004.

6. Asci, F. H., Self-concept and sport. Sports Psychology Course, P Bayar (Der). Publishing House, 1999.

7. Aine, D., Lester, D., Exercise Depression and Self Esteem. Perceptual and Motor Skills, 1995. P. 81.
8. Grogan, S., Body Image: Understanding Body Dissatisfaction in Men, Women and Children. Great Britain. Biddles Ltd, Guildford and King's Lynn, 1999.

9. Ugur, G., Relationship between Assertiveness and Body Perception in University Students. Unpublished Master Thesis. Izmir, 1996.

10. Whitehead James R., A Study of Children's Physical SelfPerceptions Using an Adapted Physical Self-Perception Profile Questionnaire. Pediatric Exercise Science.1995. 7(2): p. 132-151.

11. Altintas A., Caglar E., Asci F. H., Guven Karahan B., Uygurtas M., Gazi Journal of Physical Education and Sport Sciences. 2009. 14, p. 3-12.

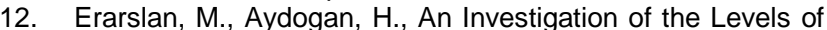
Contentment with the Body Regions of Individuals Who Do Sports in a Body Building and Fitness Center by Age and Gender Variables. CBU Journal of Physical Education and Sport Sciences, 2016.

13. Cuhadaroglu F., XXI. National Congress of Psychiatry and Neurological Sciences. 1985.

14. Aktas, I., Erhan, E. S., Investigation of Self-Esteem and Risk-Taking Levels of Individuals Who Play and Do Not Do Sports. Journal of Sports and Educational Sciences, 2015. P. 40-51.

15. Kuru, E., Bastug, G., Investigation of Personality Traits and Body Perception Levels of Football Players. Spormetre Journal of Physical Education and Sport Sciences, 2008. P. 95-101.

16. Yentur, J., Comparison of Personality Structures and Body Perception Levels of Elite Female Athletes at National Team Level. Master Thesis. Kırıkkale University, Institute of Health Sciences, 2004.

17. Erman K.A., Sahan A., Can, S., Comparison of Self-Esteem Levels of Athlete Men and Women. Akdeniz University, School of Physical Education and Sports, 2007.

18. Babalou A, Salehian MH. Relationship between Body Image Concern and Dysfunctional Attitudes in Predicting Exercise Addiction among Bodybuilders, Scientific journal of Rehabilitation Medicine, 8 (3), 231-240 